\title{
Facts, Principles, and (Real) Politics
}

\author{
Enzo Rossi
}

University of Amsterdam

\author{
Not merely bear what is necessary, still less conceal it_all idealism \\ is mendaciousness in the face of what is necessary-but love it. (Nietzsche)
}

\section{Introductory}

What should be the relationship between our factual understanding of the world and our normative theorising about it? G.A. Cohen $(2003,2008)$ has argued that if a normative principle is fact-sensitive, i.e. it relies on a factual claim for its justification, then that factual claim in turn supports the original normative principle only thanks to a further normative principle that is not fact-sensitive—so our ultimate normative principles are not constrained by facts (e.g. about feasibility, human nature, and so on). A number of others have defended or are committed to subsets of that view. ${ }^{1}$ In this paper I dispute those positions by advancing the argument that, in order to resist the conclusion that ultimate normative principles rest on facts about possibility or conceivability, Cohen has to embrace an unsatisfactory account of how principles generate normative political judgments. The critics of Cohen who reach similar or related conclusions do so by arguing that the fact-insensitivity thesis is false or trivial. My view is that there are true, non-trivial fact-insensitive normative principles, but they are unable to adequately determine how we should judge particular political states of affairs.

Wider methodological conclusions of a moderately realist ${ }^{2}$ bent follow from my more ecumenical critique of fact-insensitivity. My argument shows how the debate on facts and principles $^{3}$ and the broader Rawls-Cohen confrontation $^{4}$ are about what we want political

\footnotetext{
${ }^{1}$ See, e.g., Estlund (2011, 2014) Mason (2004), Gheaus (2013).

2 See Rossi and Sleat (2014), Rossi (2015).

3 Bocchiola and Zuolo (2013), Forcehimes and Talisse (2014), Gilabert (2010), Hall (2013), Jubb (2009), Kurtulmus (2009), de Maagt (2014), Miller (2008), Pogge (2008), Ripstein (2010), Ronzoni and Valentini (2008), Ypi (2012).

4 Recent contributions to this longstanding debate include Berkey (forthcoming), Kaufman (2014), Lippert-

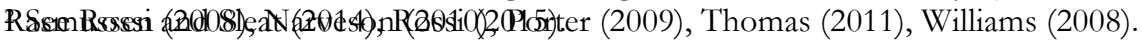

3 Bocchiola and Zuolo (2013), Forcehimes and Talisse (2014), Gilabert (2010), Hall (2013), Jubb (2009), Kurtulmus (2009), de Maagt (2014), Miller (2008), Pogge (2008), Ripstein (2010), Ronzoni and Valentini (2008), Ypi (2012).
} 
philosophy to achieve: principles ostensibly unbiased by our current understanding of human motivation and political reality, or principles capable of reliably generating political judgments? I argue that those desiderata are incompatible. Yet advocates of fact-free principles do want to guide political judgment. So, pace Cohen and many others who implicitly subscribe to his methodology, normative political principles derived purely from moral intuitions are ill-suited to their self-professed aims. Perhaps some theorists would retort that underdetermined action- or even judgment-guidance is a cost worth paying for the radical potential of fact-insensitivity. But, I maintain, that position is somewhat myopic: to be sure, our factual understanding of the world can engender status-quo bias, but there is potential for status-quo bias in our moral intuitions as well, as shown by a number of empirical studies and by a resurgence in work on ideology. A consensual separation between political philosophy and applied ethics and a return to political philosophy's traditional blend of normative and descriptive elements would be desirable—or so I shall suggest.

The paper's structure is this. In section $1 \mathrm{I}$ present Cohen's fact-insensitivity thesis. To further clarify the issues at stake, in section 2 I press an objection against it and show the implications of my argument vis-à-vis the debates on the role of feasibility constraints in normative theory, and on the interpretation of the dictum that "'ought' implies 'can". While I close the section by identifying a version of Cohen's position that can resist the objection, in section 3 I build on the earlier discussion to advance my main argument, a critique of the account of normative political judgment yielded by the intuitionism that underpins Cohen's factinsensitivity thesis. In section 4 I draw some wider methodological conclusions on ideology and varieties of status-quo bias in normative theory.

\section{Fact-insensitivity}

Cohen's position can be summarised as follows. ${ }^{5}$ A normative principle $\mathrm{P}$ may reflect or be grounded in a factual statement F; but if that is the case then $\mathrm{F}$ will always turn out to support $\mathrm{P}$ thanks to a further, fact-insensitive principle P1. As Cohen succinctly puts it:

a principle can reflect or respond to a fact only because it is also a response to a principle that is not a response to a fact" (2008: 232)

Which is to say that "where a principle $\mathrm{P}$ is affirmed in the light of certain facts, we can ask for a fact-free principle that explains why $\mathrm{P}$ is affirmed in the light of those facts." (Ibid. 246). This is Cohen's initial example (ibid.: 234):

P: We should keep our promises.

F: Only when promises are kept can promisees successfully pursue their projects.

P1: We should help people to pursue their projects.

\footnotetext{
4 Recent contributions to this longstanding debate include Berkey (forthcoming), Kaufman (2014), LippertRasmussen (2008), Narveson (2010), Porter (2009), Thomas (2011), Williams (2008).

${ }^{5} \mathrm{I}$ describe the general appeal of this position in section 4 .
} 
The point is that the (putatively) fact-insensitive principle P1 grounds fact-sensitive principle $\mathrm{P}$ and can survive the denial of factual statement F. One can affirm P1 regardless of whether one happens to believe F. And if one can find a fact-sensitive principle F1 that P1 responds to ('People can achieve happiness only if they are able to pursue their projects', say), then there must be a further fact-insensitive principle P2 that grounds F1 ('We should help people to achieve happiness', say). And so on, until the justificatory buck stops at some fact-insensitive principle somewhere down the line. ${ }^{6}$

More precisely, for Cohen fact-insensitive principles have 'logical' priority over principles whose affirmation depends on matters of fact (ibid.: 247). The use of 'logical' is questionable here, but the claim seems to be this: in the causal history of how we come to believe a principle, temporally or epistemically the facts may happen to come first, but from a justificatory point of view 'logical' priority is decisive. So the facts play no ultimate role in the justification of our normative principles.

Note that Cohen doesn't specify whether these normative principles are intended to be action-guiding or merely evaluative-in other words, whether they should provide reasons for actions or reasons for judging the normative qualities of states of affairs. As I will argue, there is reason to think that the most charitable reading of Cohen's position is the evaluative one rather than the action-guiding one. ${ }^{7}$ My argument covers both readings. In so doing it also becomes more generalisable to the wide range of positions that, as I will show, share some or all of Cohen's methodological commitments.

\section{Illuminatingly unsuccessful objections}

A straightforward way to object to Cohen's conclusion turns on what needs to be the case for a principle to be justified: in a nutshell, any normative (i.e. action- or judgment-guiding) principle must be partly grounded in an account the facts about what sorts of actions are possible or, as we'll see towards the end of this section, at least about what sorts of actions are conceivable. ${ }^{8}$ As I will show below, there is a version of Cohen's position that survives this line of objection. ' But ultimately I want to show how, once clarified, the position becomes unpalatable. In this section I push the objection outlined above to reveal what is the most plausible reading of Cohen's fact-insensitivity thesis. I propose a disambiguation between a practical and an epistemic version of the thesis, and argue that only the former survives the objection outlined above. In section 3, then, I put forward my critique of Cohen's wider position

\footnotetext{
${ }^{6}$ Cohen says that this 'recursive interrogation technique' (Pogge 2008: 458) is warranted by a 'clarity of mind requirement' (2008: 232). Yet it's not clear why Cohen should get to decide where others' justificatory chains should stop: couldn't one be sincerely satisfied with the grounding done by Fn, without having to fall back onto $\mathrm{P}(\mathrm{n}+1)$ ? Much the same could be said about causal explanations of belief in any principle. And, should Cohen wish to reply that delving deeper yields an epistemically superior philosophical outlook, he would become vulnerable to Lea Ypi's (2012) charge of infinite regress.

7 On the dangers of this retreat towards mere evaluation see Wiens (2014). The position I defend in this paper does not require as radical an indictment of evaluative justice as Wiens', but my argument is nonetheless compatible with Wiens' position.

${ }^{8}$ Regardless of how one construes the relationship between conceivability and possibility.

9 The first formulation of the objection is in Miller (2008). Also see Gilabert (2010) and Hall (2012).
} 
through a separate argument: I show that even the practical reading of the fact-insensitivity thesis yields an unpalatable account of normative political judgment, i.e. of how to assess the relative merits of alternative states of affairs.

Cohen responds to various versions of the objection by arguing that his argument is compatible with maintaining that "ought' implies 'can"'. In fact his overall project is precisely to argue for an interpretation of "'ought' implies 'can"' that does not entail that facts about what is possible for people to do should constrain what they ought to do. Or, more accurately, that any matter of fact constrains the content of (ultimate) normative principles. To clarify that claim we shall consider objections and replies to a handful of possible interpretations of it. The first version of the objection considered by Cohen is this:

Facts often make a mooted ultimate principle impossible to follow, and, since "ought" implies "can," facts thereby disqualify the mooted principle: they constitute grounds for rejecting it. (Ibid.: 250)

Cohen's reply is that the objection doesn't affect his thesis because "excluding a principle (because the facts mean it can't be complied with) isn't grounding any principle" (ibid.: 251). Two considerations are in order here. First, by Cohen's own admission, this reply saves the letter of his thesis but, by conceding that facts can refute principles, the reply makes the factinsensitivity claim look much less interesting. For that reason he then introduces a stronger version of the thesis, according to which facts can't refute principles.

Before analysing that stronger thesis, however, let's consider a stronger version of the objection. Facts can do more than merely refute principles: even unrefuted principles rely on the fact of the possibility of whatever they prescribe. Belief in a factual claim of possibility is a necessary condition for upholding Cohen's supposedly fact-free normative principles. So, in the case of the example used in the previous section, the factual principle at hand, F1, would be 'It is possible to help people to pursue their projects'. Not only can the fact of impossibility refute principles; the fact of possibility is required for us to be able to affirm them. David Miller (2008) makes this sort of point when he argues that propositions referring to facts about possibility inescapably perform a function of presuppositional grounding, i.e. the truth of such factual propositions is a necessary condition for the truth of some normative principles. Cohen does have a reply to that point:

So-called presuppositional grounding is not a form of grounding, where that means, as it has always meant in the present discussion, providing a reason for affirming. [...] That a certain action is possible is no more a reason for directing it than it is for forbidding it, nor is it part of the reason for either, since nothing can be part of the reason for something if it is equally a reason for its opposite. (2008: 336)

To clarify, Cohen's reply contains two claims: (i) an action's possibility counts in favour of it as much as it counts against it, and (ii) therefore, it can't be a ground for that action. Parsing those claims will shed light on the view at stake here.

Let us begin by noting that whether a certain fact grounds a certain action may simply be underdetermined: at least a further consideration is required to establish which action is supported by the fact at hand. Cohen would say that that further reason would have to be provided by a fact-insensitive principle. But it is not clear that the fact-insensitive principle does more grounding work than the fact - whether the fact-insensitive principle grounds the action is also underdetermined, until the relevant fact is introduced. To take the example introduced by 
Miller, the liberty principle ("respect people's will") requires (i.e. is presuppositionally grounded by) the fact of the possibility of self-conscious willing. But, Cohen replies, that fact may just as well ground the frustration principle ("frustrate people's will"), so we need a further, factinsensitive principle to have a reason to affirm the liberty principle rather than the frustration principle. However, we don't know whether the fact-insensitive principle grounds until we know the facts, and we don't know whether the facts ground until we know what the fact-insensitive principle says. Each is a necessary condition, and their conjunction is a necessary and sufficient condition for grounding. Therefore it is not clear that, as Cohen puts it, "if you have no more reason to affirm principle $\mathrm{P}$ than its opposite in the light of $\mathrm{F}$, then $\mathrm{F}$ is not even a partial ground for P." (ibid.). Perhaps a fact can be a partial ground for several incompatible normative principles-just as a principle can be a partial ground for several incompatible actions. Perhaps the fact-insensitive principle has a certain epistemic priority insofar when it reveals whether a fact supports the principle at hand, but there's no reason to think that the fact-sensitive principle plays no role in the grounding.

For Cohen "grounding" means "providing a reason for affirming". Now, reasons for affirming a principle may (at least) be epistemic or practical. We affirm a principle for epistemic reasons when we make a case for its truth. We affirm a principle for practical reasons when we make a case for acting on it. Cohen does not specify what sort of reasons he has in mind, nor does he put forward an account of the unity of reason that would back-up his position. Absent such an account, we should disambiguate Cohen's position. If the reasons for affirming a principle are epistemic my argument from underdetermination applies. If they are practical a second rejoinder becomes available to his critics. As Edward Hall (2013) points out, the letter of Cohen's position may be saved by his qualification of the notion of grounding, but the most interesting upshot of the objection holds: matters of fact may make no difference to the truth of normative principles, but they do constrain what principles it makes sense to affirm ${ }^{11}$ — for who would really care to affirm a true principle that can't apply to any actual agent? ${ }^{12}$

Both rejoinders are powerful defences of the role of factual considerations in normative theorising, yet at least the letter of Cohen's thesis is still salvageable. Consider Cohen's interpretation of the ought/can dictum:

10 Perhaps a defender of Cohen's account of grounding could invoke a version of grounding as non-reductive naturalism about moral properties (cf. Trodden 2013). But that would compromise Cohen's stated aim of remaining neutral between competing metaethical positions (2008: 257-258).

11 Here I take 'affirm' to mean something along the lines of 'maintaining that a principle is true and action- or judgment-guiding in our world'. It does make sense to state principles that don't apply to actual agents, e.g. as H.L.A. Hart (1994: 194-195) does in his discussion of the rule of law and natural rights, when he imagines that creatures with the intellectual and psychological capacities of humans but essentially physically invulnerable to each other and with no material needs they could not very easily satisfy would have quite different obligations to each other than humans. The point is that Hart's principles that only apply to imaginary creatures are useful to come to see which principles one may want to affirm (for the benefit of real creatures), but are not themselves principles one would want to affirm for human beings.

${ }^{12}$ Cohen's position on facts, principles and presuppositional grounding mirrors a point famously made by Elizabeth Anscombe (as part of a wider argument on the relationship between intention and knowledge): the command to clench one's teeth presupposes the fact that the commandee has teeth, but that presupposition does not form part of the justification for the command (2000 [1957]: 55; for a recent discussion of this point see Haddock 2011: 158160). But notice how that move only shields Cohen from the problem caused by the epistemic horn of the disambiguation. 
Anyone who rejects "one ought to do $A$ " on the sole ground that it is impossible to do $A$, anyone, that is, who would otherwise affirm that principle, is committed to this fact-insensitive principle: "One ought to do $A$ if it is possible to do $A$."

If I am right, the dictum that "ought' implies 'can"" is misused when it forms part of an attempt to show that feasibility constrains the content of ultimate normative judgment. (Ibid.)

Cohen's strategy is to remove ultimate normative questions (such as the question of what justice is) from the scope of the "'ought' implies 'can"' dictum. To do so Cohen introduces a hierarchical distinction between two levels of normative principles: ultimate principles, which are fact-free and so immune to factual constraints, and 'rules of regulation', which implement ultimate principles and, since they are devised to be followed by specific agents, are rightly subject to factual constraints (Ibid.: 253). A fully-fledged theory of justice starts upstream, from fact-insensitive ultimate principles, lest it acquire a status-quo bias. That point can be connected to Cohen's distinction between three questions in normative political theory: "(i) what is justice?; (ii) What should the state do?; (iii) Which social states of affairs ought to be brought about?" (2011: 227). The normatively ultimate concerns just question (i), because that question cannot be construed in a fact-dependent way, whereas the other two questions can be (conditionally: e.g. "what ought to be brought about, given what is possible/feasible?"). In other words, the distinction can be read as pointing out that only questions about the nature of justice are necessarily fact-free. ${ }^{13}$ So the normatively ultimate should be our primary concern, and it will take the form of a concern with the nature of justice.

Yet the focus on ultimate principles of justice only pushes back the argument into an iteration of the dialectic we explored earlier in this section, for a version of the objection introduced at the beginning of this section applies here as well. "One ought to do A if it's possible to do A" could be considered fact-dependent insofar as it requires it to be possible for us to conceive the possibility of doing A: there is a fact of the matter as to whether we can form the thought that it's possible to do A. So our nature does constrain us, though not because of limitations of will but because of cognitive limitations (of the imagination) - a point which, incidentally, could also endanger positions such as David Estlund's (2011) scepticism on the feasibility constraints posed by human nature. ${ }^{14}$

Here Cohen could reply by embracing a sort of Platonism about value, namely the view that we can know that there are true moral norms that we may be unable to conceive of. ${ }^{15}$ Yet I take it that even Cohen would be disappointed if it turned out that the normatively ultimate consisted of principles that are true but inconceivable for us; radical moralists want to be guided by the truth, not by an aspiration to an unaccessible truth. So it seems reasonable to limit the scope of the present discussion to principles we can at least hope to discover and affirm, one day.

\footnotetext{
${ }^{13}$ Not that justice is the only value that could feature in question (i) - cf. Rossi (2012).

14 Estlund's argument is complex and very different from Cohen's, so I cannot do it justice here. But if Cohen's position turned out to be untenable so would Estlund's, as his is a subset of Cohen's. For another position similar to Estlund's, but with an argument similar to Cohen's, see Mason (2004).

15 A further issue is whether such a Platonist view would commit Cohen to moral realism, and thus to grounding his principles in (moral) facts. Cohen could avoid this problem by relying on a metaethical position such as John Skorupski's irrealist cognitivism (1999, 2010), whereby the truth-aptness of normative claims doesn't require correspondence to a class of facts. Also see Bertram (2003) and Weatherson (2003).
} 
Platonism aside, should anyone wish to reply on Cohen's behalf that conceivability is a mere presupposition, and so not constitutive of the grounding relation (because whether we can know that P doesn't bear on whether we counterfactually have reason to affirm P), she would be open to the epistemic/practical disambiguation I put forward above. Either the fact of conceivability contributes (epistemically) to the justification of Cohen's conditional principle (in which case the principle would be fact-sensitive), or it would contribute to the case for acting on it (were it possible to do so).

To avoid falsifying the fact-insensitivity thesis Cohen would likely embrace a qualified version of the practical horn of the disambiguation. In fact doing so opens up one last line of reply for him, and reveals what is at stake if we commit to seeking fact-insensitive principles. Although Cohen says that a normatively ultimate principle is "a general directive that tells the agent what (they ought, or ought not) to do" (ibid.: 229), which would seem to make him vulnerable to the charge of irrelevance exposed by the practical horn of the disambiguation, he also says: "it follows from my position that justice is an unachievable (although a nevertheless governing) ideal" (Ibid.: 254, emphasis added). ${ }^{16}$ So, by Cohen's own lights, even if ultimate normative principles need not be action-guiding in the sense of containing direct prescriptions, our interest in those principles cannot be merely epistemic. In fact, while he maintains that guiding practice is not the whole purposes of political philosophy, he is clear on the importance of the practical side: "I reject that ... what I call justice does not bear on practice." (Ibid.: 306). The key issue, then, is whether Cohen's normative ultimate is a workable starting point if we want normative theory to orient us in some non-trivial sense.

\section{Intuitions, principles, political judgments}

Cohen is committed to the view that it is practically rational to affirm unachievable normative principles. Whether that is a reductio of his position or an effective reply to his critics may just be someone's modus ponens and someone else's modus tollens. To assist those who remain undecided between the two we should ask exactly in what sense justice may be unachievable and nevertheless governing. The argument in this section is the crucial one for my critique of the fact-insensitive approach. I aim to establish that any theory of 'ultimate' justice consisting entirely of fact-insensitive principles is unable to reliably generate lower-level principles for the assessment of political states of affairs.

Let us begin by noting that 'nevertheless' cannot be taken to mean 'all the same': the most straightforward way in which we may be governed by a principle (act on the basis of its guidance, that is) is simply by bringing about the state of affairs it prescribes. What Cohen seems to have in mind, then, is indirect guidance of the sort provided by principles that tell us how to rank alternative states of affairs, feasible or unfeasible. ${ }^{17}$ But if that is the case a problem emerges for Cohen's view.

\footnotetext{
16 Strictly speaking it seems to me that Cohen's position only implies that justice is not necessarily achievable. But not much hangs on this.

${ }^{17}$ I use 'feasible' and 'achievable' interchangeably, unless otherwise specified. For an interesting (but immaterial for the purposes of this paper) distinction between those notions, see Wright (2010)
} 
To approach the problem note that, crudely, assessing justice by approximation to an ideal (achievable or not) is often ill-advised, as the best can be an enemy of the good. This longstanding issue (Lipsey and Lancaster 1956, Goodin 1995: 52-56), has received considerable attention lately because of its discussion by Amartya Sen (2009). Sen contrasts 'transcendental' and 'comparative' theories of justice, where the former judge states of affairs depending on how they approximate an ideal, and the latter guide choices between pairs of alternative state of affairs. ${ }^{18}$ Cohen's position exemplifies the transcendental approach. The problem with transcendental approaches, as Sen puts it, is that a picture of a fully just society is neither necessary nor sufficient to assess the relative (comparative) merits of two alternative societal outcomes (ibid.: 15). And ranking alternatives on the basis of their distance from an ideal is not a solution to that problem because "descriptive closeness is not necessarily a guide to valuational proximity" (ibid.: 16), and because alternative scenarios may differ along different dimensions. While Sen's critique of transcendental approaches might be overdrawn (Gilabert 2012, Thomas 2013, Valentini 2011), the general point stands: in and of itself, the sort of guidance provided by descriptions of ideal states of affairs is often an inadequate guide to political judgment. Cohen may retort that judgment on specific states of affairs is a matter for rules of regulation, not for the normatively ultimate theory of justice. But the worry becomes more pressing if we consider whether the fact-insensitive approach can account for the transition from the theory of justice to the rules of regulation.

My main charge, then, is that Cohen's account of the normatively ultimate renders his theory of justice structurally incomplete. Cohen's sharp distinction between facts and principles is predicated on a form of intuitionism-or 'radical pluralism', as he calls it - that lacks the resources to solve the sort of trade-off problems that are bound to surface when we compare different alternatives to the (unachievable) perfectly just society. Consider Cohen's description of his axiological methodology:

...we determine the principles that we are willing to endorse through an investigation of our individual normative judgments on particular cases, and while we allow that principles that are extensively supported by a wide range of individual judgments can override outlier judgments that contradict those principles, individual judgments retain a certain sovereignty. (2008: 4)

Presumably, at least some of those normative judgments are made in the light of or result in fact-free principles (where else could fact-free principles come from?). So Cohen's intuitionism entails the possibility of purely normative, fact-free principles-itself a presupposition of his fact-insensitivity thesis (i.e. the view that fact-insensitive principles must be logically prior to factsensitive ones). That is to say, while intuitionism doesn't entail the fact-insensitivity thesis and is even compatible with its denial, it does entail a necessary condition for its truth; the factinsensitivity thesis requires intuitionism. Indeed it's not clear why one would want to subscribe to Cohen's intuitionism if not to uphold the fact-insensitivity thesis, especially given Cohen's explicit rejection of a faculty of moral perception (Ibid.: 4n): radically pluralist intuitionism

\footnotetext{
18 I discuss Sen's position in Argenton and Rossi (2013).
} 
provides the warrant - as it were-for grounding prescriptions in fact-free principles. ${ }^{19}$ Factsensitive principles, on the other hand, are compatible with intuitionism but do not require it.

Now, this is the upshot of Cohen's intuitionist methodology in cases of trade-offs between values:

$\ldots$ the normative requirements that we recognize present themselves in competitive array: they cannot all be satisfied all the time, nor do we have a method for systematically combining them. Discursively indefensible trade-offs are our fate. (Ibid.)

The discursive indefensibility of trade-offs may not seem much of a problem when we set out to identify ultimate normative principles, which after all is the aim of much of Cohen's work. But here we are concerned with whether those principles can guide our political agency and judgment satisfactorily - a desideratum whose importance he acknowledges by noting the 'governing' character of the normatively ultimate ${ }^{20}$ and, what is more, by insisting that high principle should guide broadly-conceived 'practice' (2009: 80) and even everyday electoral politics:

Politics is an endless struggle, and theory serves as a weapon in that struggle, because it provides a characterisation of its direction, and of its controlling purpose [...]

Considered as practical proposals, the theories of Friedman, Hayek, and Nozick were crazy [...] The theories are in that sense crazy precisely because they are uncompromisingly fundamental: they were not devised with one eye on electoral possibility. And, just for that reason, their serviceability in electoral and other political contest [sic] is very great. (Cohen 2011 [1997]: 212)

My claim is that, pace Cohen, this is where the fact-free foundations begin to endanger the viability of his edifice. Before seeing why that is the case, let us consider the 'governing role' desideratum a little longer. I take it that Cohen intends the sort of political serviceability he ascribes to 'crazy' theories to be more than purely rhetorical, or else why do political theory as opposed to advertising? In any case we'd need at least an argument to the effect that 'crazy' theory is necessary for effective propaganda. Cohen hints at such an argument:

Politicians and activists can press not-so-crasy right-wing proposals with conviction because they have the strength of conviction that depends upon depth of conviction, and depth comes from theory that is too fundamental to be practicable in a direct sense. [...] The large fundamental values help to power (or block) the little changes by nourishing the justificatory rhetoric which is needed to push (or resist) change. [...] Electoral success is to a large extent a by-product of commitment to something other than electoral success. (Ibid:: 212-214)

That is a largely empirical claim, but the evidence is not on Cohen's side: one need only think of the success of vehemently anti-intellectual far-right movements in the first half of the twentieth century ${ }^{21}$, or indeed of xenophobic populist parties in the late twentieth and early

\footnotetext{
19 That's not to say that Cohen's method in normative theory relies entirely on fact-insensitive principles. He has offered masterful arguments based on conceptual analysis of value-laden notions, e.g. negative freedom (2011 [2001]). But note how those arguments do not directly yield prescriptions.

20 To see how Cohen is concerned with the governing character of ultimate principles, also consider how he states ultimate principles (even the conditional meta-principle stated in the previous section) in deontological rather than teleological form. Perhaps Cohen's interest in justice as political philosophy's first question is best served by silence about the relationship between the good and the right; nonetheless his focus on the right is telling for our present purposes.

${ }^{21}$ Hitler's extremely successful minister of 'propaganda and enlightenment' allegedly quipped that, on hearing the word 'culture', he would reach for his revolver. The likely source of the quotation attributed to Goebbels (or sometimes Göring, or Himmler) is a line in a 1933 play by Nazi poet laureate Hanns Johst: "When I hear the word culture ... I release the safety on my Browning!” (Parkes-Perret 1984: 89).
} 
twenty-first century (Schedler 1996). ${ }^{22}$ Recall that the issue here is not just whether principles can play some causal role in politics, but whether they can play a 'governing' role in guiding politics (electoral or policy outcomes being just one indicator of such a role). Now one may charitably read Cohen as suggesting that strong theoretical foundations are a sufficient but not necessary condition for this governing role, or even necessary under specific conditions, but again the evidence hardly bears out those claims, as Western political history is littered with unsuccessful political formations fronted by intellectuals, whereas successful ones are the exception rather than the norm. ${ }^{23}$ Political influence considerable time down the line-as per Keynes' oft-quoted dictum $^{24}$ —does bless (or befall) some political theories, but that doesn't seem to be what Cohen has in mind in the above passage. Besides, even if high principles are necessary for substantial posthumous influence, it's not clear that those principles need be as high as to be fact-free, as Marx's case exemplifies. In fact one may wonder whether Marx would have had as much influence had his theory not been steeped in economics and history.

Now, Cohen does say that "the point of theory is not to generate a comprehensive social design which the politician then seeks to implement" (ibid.). Yet presumably it should be possible to see whether a specific social design follows from or at least is compatible with a theoretical principle, or else why bother formulating the principle? But it seems to me that, to use Cohen's own terminology, his approach lacks the resources to univocally identify the set of rules of regulation most suited to the application of ultimate principles to any given context. Consider how, as Michele Bocchiola and Federico Zuolo have recently shown (2013), moving from an ultimate principle to a rule of regulation introduces feasibility constraints, which in turn introduce the need to trade-off justice against other values — which in light of my point becomes a problem, as Cohen's radical pluralism offers no methodology to carry out those trade-offs. While Cohen is clear that "fundamental principles do bear on practice, since they are needed to justify the practice guiding ruler [sic] of regulation." (2008: 307), he offers no freestanding method to derive rules from principles. ${ }^{25}$

To determine whether our intuitions about specific scenarios are in line with the intuitions that underpin the ultimate theory of justice we have to fall back on intuitive judgments about cases. Cohen uses the UK Council Tax band system—whereby property tax is paid in a step-

22 One could retort that anti-intellectualism is merely a rhetorical strategy borne out of intellectually-grounded conviction. Some argue that right-wing populists draw on a rich intellectual tradition of anti-party politics (Ignazi 1996). But the scope of right-wing populism seems both broader and narrower than the anti-party stance, and the background of most leaders of contemporary right-wing populist parties suggests a genuine a-/anti-theoretical stance.

23 One of the most prominent recent examples is Michael Igniatieff's electorally disastrous stewardship of Canada's Liberal Party.

24 "The ideas of economists and political philosophers, both when they are right and when they are wrong, are more powerful than is commonly understood. [...] Madmen in authority, who hear voices in the air, are distilling their frenzy from some academic scribbler of a few years back." (2008 [1936]: 239)

25 As Andrew Forcehimes and Robert Talisse point out, "on Cohen's account part of what a normative principle directs us to do is to adopt or affirm other principles" (2013: 374). My analysis is compatible with Forcehimes' and Talisse's reading of Cohen, but I do not agree with their conclusion that fact-insensitive critiques of the factinsensitivity thesis are self-defeating. It may be a fact-insensitive truth that Cohen's fact-insensitivity thesis is true, fact-insensitive, and either trivial (Jubb 2009) or incompatible with a productive way of doing political philosophy (Hall 2013). Forcehimes and Talisse may reply that their point rests on a particular interpretation of Cohen's 'clarity of mind' requirement — in which case the considerations in footnote 6 above apply. 
functional way - as an example of a rule of regulation that is clearly inconsistent with the general principle that is supposed to guide it, namely "the broadest backs should bear the greatest burdens" (2008: 313). But the particular judgment about the bands is not deduced from the wider principle of justice. It is subject to the same epistemic test (intuitive judgment) that generates both the general principles and the particular judgments. In fact Cohen discusses some objections to his claim that the band system is unjust in light of the 'broadest backs' principle, and the dialectic between Cohen and the objector's assessment of the bands system vis-a-vis the 'broadest backs' principle turns on further intuitive judgments about hypothetical cases (ibid: 314-15). But if the assessment of the relationship between general principles and rules is left to intuition rather than inference, how exactly can principles be 'governing'?

So my main point is that Cohen plausibly attributes 'governing' standing to his ultimate principles, but then cannot ensure that this governing function is performed as the rules of regulation are selected: if when we consider alternative rules of regulation we are back to using intuitive judgments about particular cases, why bother formulating ultimate normative principles in the first place? Whenever we make an evaluative judgment-be it about competing ultimate principles or competing political compromises-we are just balancing intuitions on a particular case, so the status of fact-free principles in the process leading to our intuitive judgments on any particular political predicament remains opaque. Ultimate principles are at best one consideration among many. Their relative weight is hidden in the black box of intuition. So it is unclear how principle can "govern" the adoption of rules of regulation. The quest for the 'normatively ultimate' underdetermines what we should think about real political scenarios. ${ }^{26}$

Note that my argument doesn't require the falsity of the fact-insensitivity thesis, nor its triviality. ${ }^{27}$ Mine is a freestanding argument targeted at the guidance capability (but not at the truth) of Cohen's intuitionism. I have also shown that fact-insensitivity requires intuitionism though, so the argument also targets the guidance capability (but not the truth) of the factinsensitive approach - and by guidance I do not mean just action guidance, but even mere judgment guidance.

To see that point from a different and more informal angle, consider how Cohen says that his idea of ultimate justice as 'governing' is not about action-guidance but rather about evaluation, for political philosophy is not exclusively practice-oriented: "the question for political philosophy is not what we should do but what we should think, even when what we should think makes no practical difference." (2008: 268). Cohen does not say what we should think about. Justice, one presumes. But why think about justice? At least in part to know what to make of political states of affairs, as Cohen recognises (2008: 306, 307). And that is where my critique

\footnotetext{
26 Underdetermination is actually the best case scenario for Cohen. One could push the argument further to claim that the governing upshot of ultimate principles is indeterminable. I have no need to pursue this stronger claim here, though I find it plausible.

${ }^{27}$ So my argument differs from Robert Jubb's (2012, 2014). Crudely, Jubb's critique of Cohen is this: how does a principle's ability to explain judgments about cases not contribute (epistemically) to its justification-and isn't that a form of fact-dependence in Cohen's sense? On my view Cohen could still reply to Jubb that this relationship between facts and principles is merely a causal description of how one comes to know a principle, and doesn't feature in its justification. My own argument is immune to this line of reply, as it is able to concede it and then attack the implications of fact-insensitivity for the transition between ultimate principles and rules of regulation.
} 
resurfaces: Cohen's pluralism does not yield clear rankings of states of affairs, so it cannot guide our value judgment on political matters in a univocal way, because it does not allow us to see how ultimate principles relate to judgments about particular cases. This is not a point about how political philosophy can guide political action, but simply about what we can know about which specific political arrangements are more just than others. If knowing "what we should think" in Cohen's sense (i.e. knowing the true ultimate principles) doesn't tell us enough to know which state of affairs in a given set is the more just one, or even whether a state of affairs is to be commended or condemned, then we do not really know what we should think about what, as political philosophers, we want to think about. That is to say, we may know what we should think about justice in the abstract, but that does not tell us what we should think about our political predicament. ${ }^{28}$

So my contention is that a normative political theory can either be fact-free (in a way that requires Cohen's radical pluralism), or normatively complete (in the sense that it can, at least in principle, guide political judgment about particular cases). Cohen polemically questions this need for completeness by asking whether sometimes we demand too much of "theory in the moral realm in order to avoid, or reduce, our moral commitment" (2008: 6). But the sort of completeness I have in mind here is a relatively modest demand: I am not suggesting that factsensitive approaches will always generate judgments about particular political cases with algorithmic precision. My point is just that, since fact-sensitive approaches don't need to rely on Cohen's intuitionism, at least some of them can account for the transition from general principles to particular political judgments. Rawlsian constructivism, practice-dependence and political realism are examples of fact-sensitive approaches that, in varying degrees, eschew the problem I described above. For instance, as Alan Thomas has shown (2011 and forthcoming), Rawls' fact-sensitive, institutions-focused method has precise and demanding implications as to what system of political economy is mandated by the theory of justice as fairness. ${ }^{29}$

The burden of proof here is on Cohen: I pointed out the incompleteness of fact-insensitive theory, whereas hardly anyone claims that all normative theory is incomplete in that sense. For instance, the difference principle may have underdetermined political implications, ${ }^{30}$ but many consequentialist theories' prescriptions are both detailed and demanding. ${ }^{31}$

Besides, it is not as if Cohen's normatively ultimate clearly places strict demands on our moral commitment anyway, since we cannot know what its demands are in any specific political

\footnotetext{
28 This point may well generalise from politics to ethics, and even to other domains of normativity; but exploring those themes would take us beyond the remit of this paper.

29 "It is true that, to discharge its task, the initial model of our inchoate intuitions about liberty, equality and justice is an abstract one. We then confirm the model in wide reflective equilibrium. We then further proceed to derive further, surprising, consequences from the model. We discover that the only way in which our society can be just is if it implements one, determinate, form of economy: either a property-owning democracy or liberal market socialism." (Thomas, forthcoming, 11)

${ }^{30}$ If that's the case - a point on which I press no views here- it may be due to the fact that, as some have argued, perhaps the method of reflective equilibrium isn't sufficiently different from intuitionism. For a critical discussion see Brun (2014).

31 E.g. Singer (1972), which follows in a long tradition that goes at least as far as Bentham's detailed and ethicallygrounded designs for the Panopticon.
} 
predicament. Fact-free principles may well be free of the sort of status quo bias ${ }^{32}$ Cohen finds in (e.g.) Rawlsian constructivism, but that freedom comes at the cost of his theory's ability to guide not just our political action, but even our political judgment in an unequivocal manner. Political philosophers have a choice as to which bullet to bite.

\section{The status quo, ideology, and other biases}

Let us now briefly weigh up those two bullets. The main case against the fact-sensitive (or realist) bullet, and for the fact-insensitive (or moralist) one, is that fact-sensitivity is plagued by status quo bias-notably the facts about human motivation that Cohen thinks Rawls is wrong to allow in the original position ${ }^{33}$ (those facts are the contemporary equivalent of the theories of human nature and travel reports from the New World used by early modern social contract theorists to characterise their accounts of the state of nature). But the appeal of fact-insensitivity extends beyond its role in Cohen's critique of Rawls. For one thing, fact-insensitivity can be used to isolate Cohen's preferred theory of justice, luck egalitarianism, from the charge that some of its tenets (e.g. the distinction between brute and option luck) are impracticable. Moreover, the pursuit of fact-insensitive principles can be considered an extension of the Kantian project of discovering the principles of pure practical reason ${ }^{34}$ - here the appeal would consist not so much in avoiding status quo bias, but rather in identifying principles of right action that apply regardless of agents' empirically-determined preferences about the good.

Whether those appealing features of fact-insensitivity are enough to counterbalance the problem with judgment-guidance I have identified will depend, to a significant extent, on one's wider philosophical commitments. For our more limited purposes, let us focus on the more selfcontained and ecumenical problem of status quo bias. Is fact-insensitivity less status quo-biased than the alternative? To see that our intuitive, fact-free normative judgments may be comparably biased one needn't go as far as to agree with Raymond Geuss (and Nietzsche) that "Ethics is usually dead politics: the hand of a victor in some past conflict reaching out to try to extend its grip to the present and the future." (2010a: 42). ${ }^{35}$ Nor does one need to agree with Sally Haslanger on the pervasive influence of ideology: “...our meanings are not transparent to us: often ideology interferes with an understanding of the true workings of our conceptual framework and our language." (2012: 383). Suffice it to observe that, as many philosophical and psychological studies confirm, ${ }^{36}$ our moral intuitions must relate in some non-trivial way to our present practices, if only because, whatever else it may be, morality is one of the practices we are engaged in. To deny that Cohen would have to give up his claim that his position is neutral

\footnotetext{
32 Note how, relatedly, my argument doesn't require me to take a stand on the lively debate on whether feasibility constraints should limit the scope of justice: feasibility constraints are only one of the classes of facts that may ground principles, and in any case I am not committed to denying the fact-insensitivity thesis.

33 2008: 231-232. One could agree with Cohen that the parties in the original position shouldn't know the facts about inequality and motivation without having to subscribe to Cohen's fact-insensitivity thesis: the argument could simply be that Rawls is wrong to think that those facts cannot be changed by implementing the correct theory of justice. The argument would be about the contents of the feasible set, rather than about the relationship between feasibility and justice.

34 Thanks to an anonymous reviewer for highlighting this point.

35 I discuss this position in some detail in Rossi (2010), and the wider issue in Jubb and Rossi (forthcoming).
} 
between competing metaethical views (2008: 257-258), and arguably even his claim that he need not posit a faculty of moral perception (ibid.: $4 \mathrm{n}$ ). In either case the moralist position would have acquired one type of bias to avoid another.

To be sure, that point and the foregoing discussion do not establish that fact-insensitive ultimate principles derived exclusively from moral intuitions are as biased as fact-sensitive ones, but then neither does Cohen conclusively establish that constructivist (or practice-dependent, or realist) bias is worse than intuitionist bias. We would need no less than a full theory of ideology to carry out that comparison exhaustively - extant theories of ideology incline against moral intuition-driven political philosophy, anyhow (Prinz and Rossi forthcoming). Indeed, part of what my argument shows is that future work on the methodology of political philosophy will require more attention to this traditional concern. ${ }^{37}$ At any rate, if Cohen's normatively ultimate principles aren't quite as unbiased as he suggests, and if they are also ill-suited to their selfprofessed aim of being 'governing', then we may want to renounce theorising about values that float free and above the facts, and return to political philosophy's traditional haunt between facts and values. ${ }^{38}$

\section{References}

Anscombe GEM (2000 [1957]). Intention. Harvard University Press, Cambridge, MA.

Argenton C, Rossi E (2013) Pluralism, Preferences, and Deliberation: A Critique of Sen's Constructive Argument for Democracy. Journal of Social Philosophy 44:129-145.

Berkey B (forthcoming) Double Counting, Moral Rigorism, and Cohen's Critique of Rawls: A Response to Alan Thomas. Mind.

Bertram C (2003) Cohen on Facts and Principles. Crooked Timber http://crookedtimber.org/2003/07/31/cohen-on-facts-and-principles/. Accessed 15 June 2014.

Bocchiola M, Zuolo F (2013) On Justice and Other Values: G.A. Cohen's Political Philosophy and the Problem of Trade-Offs. Philosophical Papers 42:1-24.

Brun G (2014) Reflective Equilibrium Without Intuitions? Ethical Theory and Moral Practice 17:237252.

Cohen GA (1997) Back to Socialist Basics. New Left Review 207:3-16.

Cohen GA (2011 [2001]) Freedom and Money. In: On The Currency of Egalitarian Justice and Other Essays in Political Philosophy. Princeton University Press, Princeton, NJ, pp 166-202.

\footnotetext{
36 See, for example, De Cruz (2014), Nadelhoffer and Feltz (2008), O’Neill and Petrinovich (1998).

${ }^{37}$ Cf. Freeden (2013) and Rossi (forthcoming).

38 While any mistakes remain mine, I'm grateful to many colleagues for their feedback on this paper, which was presented at the Universities of Amsterdam, Copenhagen, KU-Leuven, Manchester, Pavia, South Wales, and Stirling. I'd also like to thank Michele Bocchiola, Ryan Cox, Luara Ferracioli, Anca Gheaus, Ed Hall, Rob Jubb, Naomi Goulder, Sune Lægaard, Richard North, Juha Räikkä, Alan Thomas, Martin Van Hees, Nicholas Vrousalis, and Federico Zuolo for their acute comments.
} 
Cohen GA (2003) Facts and Principles. Philosophy and Public Affairs 31:211-245.

Cohen GA (2008) Rescuing Justice and Equality. Harvard University Press, Cambridge, MA.

Cohen GA (2009) Why Not Socialism? Princeton University Press, Princeton, NJ.

Cohen GA (2011) How To Do Political Philosophy. In: On The Currency of Egalitarian Justice and Other Essays in Political Philosophy. Princeton University Press, Princeton, NJ, pp225-235.

De Cruz H (2014) Where Philosophical Intuitions Come From. Australasian Journal of Philosophy doi:10.1080/00048402.2014.967792.

Estlund D (2011) Human Nature and the Limits (If Any) of Political Philosophy. Philosophy \& Public Affairs 39:207-237.

Estlund D (2014) Utopophobia. Philosophy \& Public Affairs 42:113-134.

Forcehimes AT, Talisse RB (2013) Clarifying Cohen: A Response to Jubb and Hall. Res Publica 19:371-379.

Freeden M (2013) The Political Theory of Political Thinking. Oxford University Press, Oxford.

Geuss R (2010a) Politics and the Imagination. Princeton University Press, Princeton, NJ.

Geuss R (2010b) Realismus, Wunschdenken, Utopie. Deutsche Zeitschrift für Philosopbie 58:419-429.

Gheaus A (2013) The Feasibility Constraint on The Concept of Justice, Philosophical Quarterly 63:445-464.

Gilabert P (2012) Comparative Assessments of Justice, Political Feasibility, and Ideal Theory. Ethical Theory and Moral Practice 15: 39-56.

Gilabert P (2010) Feasibility and Socialism. Journal of Political Pbilosophy 19:52-63.

Goodin RE (1995) Political Ideals and Political Practice. British Journal of Political Science 25:37-56.

Haddock A (2011) "The Knowledge That a Man Has of His Intentional Actions". In: Ford A, Hornsby J, Stoutland, F (eds) Essays on Anscombe's Intention. Harvard University Press, Cambridge, MA, pp147-169.

Hall E (2013) Political Realism and Fact-Sensitivity. Res Publica 19: 173-181.

Hart HLA (1994 [1961]) The Concept of Law, 2nd edn. Oxford University Press, Oxford.

Haslanger S (2012) Resisting Reality. Oxford University Press, Oxford.

Ignazi P (1996) The Intellectual Basis of Right-Wing Anti-Partyism. European Journal of Political Research 29: 279-296.

Jubb R, Rossi E (forthcoming) Political Norms and Moral Values. Journal of Philosophical Research.

Jubb R (2014) Recover It From the Facts as We Know Them: Practice Dependence's Predecessors. Journal of Moral Philosopby 6:1-23. 
Jubb R (2009) Logical and Epistemic Foundationalism About Grounding: The Triviality of Facts and Principles. Res Publica 15:337-353.

Kaufman A, ed. (2014) Distributive Justice and Access to Advantage: G.A. Cohen's Egalitarianism. Cambridge University Press, Cambridge.

Keynes JM (2008 [1936]) The General Theory of Employment, Interest and Money. BN Publishing, Milton Keynes.

Kurtulmus AF (2009) Rawls and Cohen on Facts and Principles. Utilitas 21:489-505.

Lippert-Rasmussen K (2008) Publicity and Egalitarian Justice. Journal of Moral Philosophy 5:30-49.

Lipsey RG, Lancaster KJ (1956) The General Theory of Second Best. Review of Economic Studies, 24:11-33.

De Maagt S (2014) In Defence of Fact-Dependency. Canadian Journal of Philosophy. doi:10.1080/00455091.2014.955268.

Mason A (2004) Just Constraints. British Journal of Political Science 34:251-268.

Miller D (2008) Political Philosophy for Earthlings: Against Cohen on Facts and Principles. In: Leopold D, Stears M (eds) Political Theory: Methods and Approaches. Oxford University Press, Oxford.

Nadelhoffer T, Feltz A (2008) The Actor-Observer Bias and Moral Intuitions: Adding Fuel to Sinnott-Armstrong's Fire. Neuroethics 1:133-144.

Narveson J (2010) Cohen's Rescue. Journal of Ethics 14:263-334.

O’Neill P, Petrinovich L (1998) A Preliminary Cross-Cultural Study of Moral Intuitions. Evolution and Human Behavior 19:349-367

Parkes-Perret FB, ed. (1984) Hanns Johst's Naz̨i Drama Schlageter. Akademischer Verlag HansDieter Heinz, Stuttgart.

Pogge TW (2008) Cohen to the Rescue! Ratio 21:454-475.

Porter T (2009) The Division of Moral Labour and the Basic Structure Restriction. Politics, Philosophy and Economics 8:173-199.

Prinz, J, Rossi, E (forthcoming) Political Realism as Ideology Critique. Critical Review of International Social and Political Philosophy.

Ripstein A (2010) Critical Notice: G.A. Cohen, Rescuing Justice and Equality. Canadian Journal of Philosophy 44:669-700.

Ronzoni M, Valentini L (2008) On the Meta-Ethical Status of Constructivism: Reflections on G.A. Cohen's "Facts and Principles." Politics, Philosophy \& Economics 7:403-422.

Rossi E (forthcoming) Can Realism Move Beyond a Methodenstreit? Political Theory. 
Rossi E (2015) Being Realistic and Demanding the Impossible. SSRN Working Paper. http://dx.doi.org/10.2139/ssrn.2555335 Accessed 5 June 2015.

Rossi E, Sleat M (2014) Realism in Normative Political Theory. Philosophy Compass 9: 689-701.

Rossi E (2012) Justice, Legitimacy, and (Normative) Authority for Political Realists. Critical Review of International Social and Political Philosophy 15: 149-164.

Rossi E (2010) Reality and Imagination in Political Theory and Practice: On Raymond Geuss' Realism. European Journal of Political Theory 9: 504-512.

Schedler A (1996) Anti-Political-Establishment Parties. Party Politics 2:291-232.

Sen A (2009) The Idea of Justice. Harvard University Press, Cambridge, MA.

Singer P (1972) Famine, Affluence, and Morality. Philosopby and Public Affairs 1:229-243.

Skorupski J (1999) Irrealist Cognitivism. Ratio 12:436-459.

Skorupski J (2010) The Domain of Reasons. Oxford University Press, Oxford.

Thomas A (2011) Cohen's Critique of Rawls: A Double Counting Objection. Mind 120:10991141.

Thomas A (2013) Sen on Rawsl" "Transcendental Institutionalism". European Journal of Political Theory doi: $10.1177 / 1474885113495202$

Thomas A (forthcoming) Rawls and Political Realism: Realistic Utopianism or Judgment in Bad Faith? European Journal of Political Theory.

Trogdon K (2013) An Introduction to Grounding. In: Hoeltje M, Schnieder B, Steinberg A (eds) Dependence. Philosophia Verlag, Berlin.

Valentini L (2011) A Paradigm Shift in Theorizing About Justice? Economics and Philosophy 27:297315.

Ypi L (2012) Facts, Principles and the Third Man. Socialist Studies/Études socialistes 8:196-215.

Weatherson B (2003) Ethical Naturalism Reredux. Crooked Timber http://crookedtimber.org/2003/07/30/ethical-naturalism-reredux/ Accessed 15 June 2014.

Wiens D (2014) 'Going Evaluative' to Save Justice from Feasibility: A Pyrrhic Victory. Philosophical Quarterly 64:301-307.

Williams A (2008) Justice, Incentives and Constructivism. Ratio 21:476-493.

Wright EO (2010) Envisioning Real Utopias. Verso, London. 